\title{
REGULAÇÃO JURÍDICA, MEIO AMBIENTE E ENERGIA: DESAFIOS E OPORTUNIDADES DA GERAÇÃO DISTRIBUÍDA EM ÁREAS URBANAS
}

\section{LAW, ENVIRONMENT AND ENERGY: CHALLENGES AND OPPORTUNITIES OF THE DISTRIBUITED GENERATION IN URBAN AREAS}

Leonardo Papp ${ }^{1}$

\section{Resumo}

Este artigo tem por objetivo apresentar reflexões (iniciais) acerca da relação entre meio ambiente, produção de energia e regulação jurídica, aplicadas ao contexto específico das denominadas microgeração e minigeração, como modalidades de geração distribuída de energia que podem ser implantadas em áreas urbanas. A partir de pesquisa bibliográfica acerca do assunto, o artigo aborda (i) as vantagens da adoção de tais iniciativas, no que se refere à mitigação de impactos ambientais, (ii) o marco legal atualmente vigente para tais instrumentos, (iii) o potencial de crescimento e ampliação de sua utilização, (iv) além de serem apresentados alguns apontamentos iniciais sobre como a legislação (Direito), na forma atualmente estruturada no sistema legal brasileiro, pode ajudar (ou atrapalhar) a consecução de tais benefícios em termos concretos. Ao final, conclui-se que a geração distribuída em áreas urbanas é ferramenta importante para a compatibilização entre proteção ambiental e produção de energia, cuja efetivação está diretamente associada à sua adequada disciplina jurídica, notadamente no que se refere à articulação das inciativas de regulação oriundas de todos os entes públicos envolvidos.

Palavras-chave: direito, meio ambiente, energia, geração distribuída, áreas urbanas.

\section{Abstract}

This article aims to present initial considerations on the relationship between environment, energy production and legal regulation, applied to the specific context of the so-called "microgeneration"

\footnotetext{
1 Professor de Direito Ambiental e Direito Imobiliário (CatólicaSC). Doutor em Direito Econômico e Socioambiental (PUCPR). Pesquisador Visitante na Pace School of Law (NY/EUA). Mestre em Direito Ambiental (UFSC). Especialista em Direito Imobiliário (PUCPR). Advogado. Centro Universitário Católica de Santa Catarina (CatólicaSC). Brasil. E-mail: leonardo@papp.adv.br
} 
and "minigeneration", as modalities of "distributed generation" of energy, that can be implanted in urban areas. Based on bibliographical research , the article addresses (i) the advantages of adopting such initiatives with regard to mitigation of environmental impacts, (ii) the current legal framework for such instruments, (iii) the potential for growth and expansion of its use, (iv) in addition to presenting some initial notes on how legislation (Law), as currently structured in the Brazilian legal system, can help (or inhibit) the attainment of such benefits in concrete terms. It is concluded that distributed generation in urban areas is an important tool for the compatibility between environmental protection and energy production, whose implementation is directly associated to its adequate legal regulation, especially relating to articulation of the regulatory initiatives of all public entities involved.

Keywords: law, environment, energy, distributed generation, urban areas.

\section{INTRODUÇÃO}

Este artigo tem por objetivo apresentar reflexões (iniciais) acerca da relação entre meio ambiente, produção (e consumo) de energia e regulação jurídica, aplicada ao contexto específico das denominadas microgeração e minigeração, como modalidades de geração distribuída de energia que podem ser implantadas em áreas urbanas.

Partindo da premissa de que a noção de desenvolvimento sustentável fundamenta o modelo de proteção (jurídica) do meio ambiente na legislação brasileira, inicialmente se busca contextualizar o caráter potencialmente (inerentemente) conflituoso entre (promoção e manutenção da) qualidade ambiental e (produção e consumo de) energia, ambas consideradas elementos essenciais para a concretização da dignidade da pessoa humana, na condição de princípio-fim do Estado (e Direito) brasileiro.

Diante desse contexto, passa-se a abordar os principais aspectos da regulação jurídica da produção e consumo de energia no Brasil, destacando-se o despertar de inciativas locais, difusas e de pequena escala, que podem ser implantadas inclusive em áreas urbanas, por meio da adoção do modelo denominado geração distribuída, sob as formas de minigeração ou de microgeração.

Para aprofundar a análise da temática proposta, abordam-se (i) as vantagens da adoção de tais iniciativas, no que se refere à mitigação de impactos ambientais, (ii) o marco legal atualmente vigente para tais instrumentos, (iii) o potencial de crescimento e ampliação de sua utilização, além de serem apresentados (iv) alguns apontamentos iniciais sobre como a legislação (Direito), na forma 
atualmente estruturada no sistema legal brasileiro, pode ajudar (ou atrapalhar) a consecução de tais benefícios em termos concretos.

Ao final do texto são apresentadas de modo sintetizado as conclusões obtidas a partir das informações levantadas, as quais apontam na direção da necessidade de reconhecer a geração distribuída em áreas urbanas como importante instrumento de compatibilização entre proteção ambiental e produção de energia, sendo que o aproveitamento efetivo do seu potencial está diretamente associado à adequada disciplina jurídica da matéria, notadamente no que se refere à articulação das inciativas de regulação oriundas de todos os entes públicos envolvidos.

\section{DESENVOLVIMENTO SUSTENTÁVEL COMO FUNDAMENTO DA TUTELA (JURÍDICA) DO MEIO AMBIENTE: CONTEXTUALIZAÇÃO}

De modo mais acentuado ao longo dos últimos 40 anos, a noção de desenvolvimento sustentável vem assumindo papel central na agenda geopolítica mundial, sendo apresentado como modelo de produção/consumo que (supostamente) seria capaz de mitigar/equacionar os impactos que as atividades humanas causam no meio ambiente global. ${ }^{2}$

Não se afigura despropositado afirmar que um dos marcos fundamentais desse movimento foi o Relatório Nosso Futuro Comum (Brundtland), resultado das atividades realizadas pela Comissão Mundial sobre Meio Ambiente e Desenvolvimento da ONU, segundo o qual seria sustentável "O desenvolvimento que satisfaz as necessidades presentes, sem comprometer a capacidade das gerações futuras de suprir suas próprias necessidades" (FGV, 1991).

Com o passar do tempo e o aprofundamento da discussão em torno do assunto, a ideia de desenvolvimento sustentável tem seu campo de abrangência ampliado, inserindo-se elementos que não estão diretamente relacionados aos recursos naturais. Trata-se do chamado tripé da sustentabilidade (triple botton line), de acordo com o qual o desenvolvimento sustentável é aquele capaz de assegurar condições ecologicamente equilibradas, socialmente justas e economicamente viáveis, tanto para a presente quanto para as futuras gerações.

Mais recentemente - e com intensa participação do Estado brasileiro - esse modelo de desenvolvimento sustentável foi reafirmado, por ocasião da Conferência das Nações Unidas sobre

\footnotetext{
${ }^{2} \mathrm{O}$ conteúdo do termo desenvolvimento sustentável (ou sustentabilidade) não encontra plena convergência nos estudos dedicados ao tema. Sobre o assunto, cf. BELL (2008). Para uma análise sobre a relação entre sustentabilidade e direito, cf. FREITAS (2012). Para uma abordagem crítica quanto ao potencial da sustentabilidade, como paradigma de desenvolvimento, cf. PERRET (2011).
} 
Desenvolvimento Sustentável (Rio+20). Tanto é assim que, em documento final, intitulado "O Futuro que Queremos", foi expressamente renovado o compromisso dos países signatários, entre os quais o Brasil, "com o desenvolvimento sustentável e com a promoção de um futuro econômico, social e ambientalmente sustentável para o nosso planeta e para as atuais e futuras gerações" (MMA, 2014).

Todo esse movimento (internacional), na direção de eleger o desenvolvimento sustentável como base (política, teórica, etc.) para orientar a relação do ser humano com o meio ambiente, não passou despercebido no plano nacional. Ao contrário, os postulados atribuídos ao desenvolvimento sustentável vêm determinando decisivamente a elaboração da legislação ambiental em diversos países, inclusive no Brasil.

A influência da noção de desenvolvimento sustentável no ordenamento jurídico brasileiro pode ser especialmente percebida pela multiplicidade de valores (constitucionais) voltados à dignidade da pessoa humana (art. 3ㅇ, I CRFB/88), alçada à condição de princípio-fim da ordem constitucional e do próprio Estado. ${ }^{3}$ Isso porque, no sistema jurídico pátrio, o pleno atendimento do objetivo fundamental de promover condições de vida digna para toda pessoa humana ${ }^{4}$ (i) se estende desde logo também às futuras gerações, contemplando a noção de equidade intergeracional (art. 225, caput CRFB/88) e (ii) e açambarca não apenas valores (jurídicos) destinados a assegurar que o meio ambiente se mantenha em patamar ecologicamente equilibrado (art. 225, caput), considerado isoladamente, mas concomitantemente também valores (jurídicos) mais estritamente ligados a aspectos sociais (v.g., redução das desigualdades regionais, art. 3ำ, III CRFB/88; a busca do pleno emprego, art. 170, VIII CRFB/88), assim como à realização de atividades (produtivas) econômicas (v.g., a liberdade de iniciativa econômica, art. 170, caput CRFB/88).

Em suma, sob o influxo da agenda internacional, ao longo das últimas décadas e especialmente a partir da promulgação da Constituição Federal de 1988, o sistema jurídico brasileiro

\footnotetext{
${ }^{3} \mathrm{O}$ reconhecimento da dignidade da pessoa humana como princípio-fim, no contexto da ordem econômica e, por conseguinte, da própria tutela do meio ambiente - é assim expressado por Silva (1998, p. 43): "[...] a determinação constitucional segundo a qual as ordens econômica e social têm por fim realizar a justiça social constitui uma norma-fim, que permeia todos os direitos econômicos e sociais, como, também, toda a ordenação constitucional, porque nela se traduz um princípio político constitucionalmente conformador, que se impõe ao aplicador da Constituição. Os demais princípios informadores da ordem econômica - propriedade privada, função social da propriedade, livre concorrência, defesa do consumidor, defesa do meio ambiente, redução das desigualdades sociais e regionais, busca do pleno emprego - são da mesma natureza. Apenas esses princípios preordenam-se e hão que se harmonizar em vista do princípio-fim que é a realização da justiça social, a fim de assegurar a todos existência digna".

${ }^{4}$ Não se adentrará nesse momento, por desbordar os objetivos e limites deste trabalho, na discussão em torno do caráter antropocêntrico ou não-antropocêntrico da relação entre o ser humano e o meio ambiente, bem como a repercussão disso na formação e aplicação do sistema jurídico de tutela ambiental. Sobre o tema, no âmbito da ética ambiental, cf. McSHANE (2007).
} 
vem se estruturando a partir dos postulados ligados à noção genérica de desenvolvimento sustentável, colocando a pretensão de compatibilizar equilíbrio ecológico, justiça social e viabilidade econômica de atividades produtivas como elemento central do conteúdo (e da efetividade) da dignidade da pessoa humana, na condição de princípio-fim do próprio Estado.

\section{DESENVOLVIMENTO SUSTENTÁVEL, MEIO AMBIENTE E PRODUÇÃO (E CONSUMO) DE ENERGIA}

Note-se que, ao identificar a necessidade de harmonização entre os diversos vetores da sustentabilidade, também se está reconhecendo o caráter inerentemente conflituoso entre os vários aspectos inseridos no modelo de desenvolvimento sustentável, de modo que "há, portanto, uma tensão dialética permanente entre o objetivo de proteção ambiental e o desenvolvimento econômico" (SARLET; FENSTERSEIER, 2010, p. 21).

Numa palavra, tanto no âmbito teórico quanto no plano fático, a consolidação do desenvolvimento sustentável como paradigma do sistema constitucional brasileiro inevitavelmente conduz a situações de intensa litigiosidade, ${ }^{5}$ na medida em que as opções (legislativas, de políticas públicas, etc.) que sejam adotadas em relação a algum dos aspectos envolvidos (ambiental, social ou econômico) impactam (positiva ou negativamente) na qualidade e disponibilidade dos demais, seja no presente ou num cenário temporalmente mais alargado (de modo a abranger também as futuras gerações).

Essa tensão (interna) entre os objetivos do desenvolvimento sustentável pode ser verificada de forma bastante evidente, por exemplo, na relação entre a manutenção da qualidade do meio ambiente e a produção (e o consumo) de energia.

Especialmente a partir da segunda metade do século XX, a demanda por (e a capacidade de geração de) energia aumentou exponencialmente em praticamente todos os países. No caso brasileiro, especificamente no que se refere à eletricidade, entre os anos 1970 e 2004, o consumo

\footnotetext{
${ }^{5}$ De acordo com a lição de Rodolfo Mancuso (2011, pp. 100-103), os direitos difusos têm como uma de suas características próprias a intensa litigiosidade interna, haja vista que, "no campo dos interesses difusos, outra coisa se dá: eles estão soltos, desagregados, disseminados entre segmentos sociais mais ou menos extensos; não têm um vínculo jurídico básico que os coaliza, mas exsurgem de agultinações contingenciais, não raro contrapostas entre si. [...] E essas necessidades e esses interesses, de massa, sofrem constantes investidas, frequentemente também de massa, contrapondo grupo versus grupo, em conflitos que se coletivizam em ambos os polos. [...] Em todos esses casos, a marcante conflituosidade deriva basicamente da circunstância de que todas essas pretensões metaindividuais não têm por base um vínculo jurídico definido, mas derivam de situações de fato, contingentes, por vezes até ocasionais. [...] têm-se que a esse nível, todas as posições, por mais contrastantes, parecem sustentáveis. É que nesses casos de interesses difusos, não há parâmetro jurídico que permita um julgamento axiológico preliminar sobre a posição 'certa' e 'errada'”.
} 
total dessa forma de energia cresceu nada menos que 906,43\%, passando de 39.668 GWh para 359.564 GWh (EPE, 2006, p. 8).

Não parece haver controvérsias sobre o importante papel que o incremento dos níveis de fornecimento de energia desempenhou na transformação econômica do Brasil, pois consubstancia insumo necessário para a viabilidade da realização (e expansão) de atividades produtivas, em todos os setores (industrial, comercial, serviços, agropecuário, etc.). Da mesma forma, nos dias atuais, dificilmente se poderia reconhecer a existência de condições mínimas de vida digna para populações (ou indivíduos) que estejam (completamente) privados do acesso à energia, cuja utilização viabiliza o funcionamento de equipamentos e tecnologias que estão associados à própria qualidade de vida.

Por outro lado (e não obstante seu papel para o desenvolvimento econômico e social brasileiros), de modo cada vez mais intenso a questão energética também vem sendo colocada no centro nas discussões ambientais do país, na medida em que a ampliação do sistema de geração (distribuição e consumo) de energia causa inevitavelmente impactos negativos no meio ambiente. ${ }^{6}$

Os desafios ambientais relacionados à geração (distribuição e consumo) de energia no país podem ser verificados, por exemplo, no âmbito da Política Nacional sobre Mudança do Clima PNMC, através da qual o Brasil impôs a si o compromisso de adotar ações de mitigação das emissões de gases de efeito estufa, com vistas a reduzir entre $36,1 \%$ e 38,9\% suas emissões projetadas até 2020 (art. 12, LF 12.187/09). Para se atingir tal objetivo, as medidas de mitigação atinentes especificamente ao setor energético assumem papel relevante. Isso porque, da projeção total das emissões nacionais de gases de efeito estufa para o ano de 2020, estimada em 3.236 milhões de ton $\mathrm{CO}_{2}$ eq, apenas o setor de produção e uso de energia representa algo em torno de $26,82 \%$ ou 868 milhões de ton $\mathrm{CO}_{2}$ eq (art. 5o, II DF 7.390/10). . Diante desse contexto, a PNMC indica a necessidade de serem evitadas $27 \%$ (ou 234 milhões de tonCO ${ }_{2}$ eq) das emissões associadas à produção e consumo de energia projetadas para o período, o que representa 7,23\% da redução total necessária

\footnotetext{
${ }^{6}$ Os impactos podem variar de acordo com a matriz escolhida, mas sempre existirão. Mesmo nas chamadas fontes renováveis ou fontes limpas de energia. Por exemplo, no caso da energia hidrelétrica, embora utilize uma fonte de geração considerada renovável (o que já é motivo de controversa em si), frequentemente as etapas de implantação de usinas causam impactos ambientais significativos, decorrentes da ocupação de extensas áreas para o armazenamento de água e da supressão de vegetação para a implantação de linhas de transmissão. No mesmo sentido, embora a energia nuclear seja considerada uma fonte limpa (em razão do reduzido nível de resíduos e de emissões que produz), seu potencial degradador também é elevado, notadamente em situações de acidentes durante a operação, bem como em razão das dificuldades técnicas relacionadas à adequada disposição e neutralização de rejeitos radioativos.

${ }^{7}$ Nas projeções realizadas no âmbito da PNMC, a participação do setor energético na emissão de gases de efeito estufa somente é menor do que a contribuição decorrente da mudança de uso da terra (notadamente, desmatamento), com 1.404 milhões de tonCO $\mathrm{CO}_{2}$ eq.
} 
para que o Brasil atinja a meta que foi estabelecida (Anexo, item 2 DF 7.390/10).

\section{O DESPERTAR DE INICIATIVAS LOCAIS, DIFUSAS E DE PEQUENA ESCALA DE GERAÇÃO DE ENERGIA COMO ALTERNATIVA PARA ÁREAS URBANAS}

Fica evidente, portanto, o cenário de (potencial) conflituosidade quando se está diante da relação entre (a proteção e promoção do) meio ambiente e (a produção e consumo de) energia, o que desperta novos desafios para diversas áreas do conhecimento. O Direito brasileiro, em todas suas formas de manifestação, não permaneceu alheio a essa realidade, tendo despontado nos últimos anos insipiente doutrina, bem como diversos diplomas legais que abordam a disciplina jurídica da produção, distribuição e consumo de energia, em vista de seus impactos ambientais. ${ }^{8}$

Ocorre que, assim como usualmente se verifica em outros temas de direito e legislação ambiental, também a relação entre meio ambiente e energia costuma ser estudada e regulada quase exclusivamente numa perspectiva concentrada em poucos atores e cuja menor escala de reflexão é o âmbito nacional. Tal circunstância pode estar associada a diversos fatores, entre os quais, (i) no campo estritamente jurídico, a posição de prominência regulatória que a União assume, na medida em que the foi privativamente conferida competência administrativa (art. 21, I CRFB/88) e legislativa (art. 22, II CRFB/88) quanto à matéria energética, além da elaboração de normas de caráter geral em temas de meio ambiente (art. 24, § 1으 CRFB/88), (ii) no campo do planejamento para o setor, a prioridade conferida a empreendimentos de porte significativo, que podem individualmente representar inputs mais consideráveis para atender à crescente demanda por energia, (iii) mesmo raciocínio que preside de forma amplamente majoritária as preocupações quanto aos (potenciais e efetivos) impactos ambientais do setor, normalmente enfocados nesses mesmos empreendimentos de porte significativo, os quais tendem a causar isoladamente níveis de degradação mais elevados.

Como consequência disso, se estabeleceu (equivocadamente) a impressão de que a regulação jurídica do setor de energia - seja no que concerne à sua produção e consumo, quanto no que diz respeito aos seus impactos no meio ambiente -, é algo que necessariamente deveria ser analisado e regulado de forma concentrada e em grande escala, sendo tema restrito à atuação da União e voltado fundamentalmente às diversas etapas (instalação, operação, geração, distribuição etc.) de grandes empreendimentos.

Paulatinamente, entretanto, vêm despertando a percepção de que a regulação jurídica dos

\footnotetext{
${ }^{8}$ Sobre o tema, cf., exemplificativamente, FERREIRA (2015), COSTA (2014) e SOARES (2014).
} 
temas ambientais também deve estar voltada para a adoção de medidas de pequena escala, difusas e que se estabelecem no âmbito local (NOLLON, 2014). Exemplo dessa nova concepção são as formas alternativas e ainda pouco convencionais de geração e consumo de energia, dentre as quais despontam as chamadas minigeração e microgeração, com especial potencial de aproveitamento em áreas urbanas. Ocorre que os estudos no campo jurídico ainda não têm atribuído atenção suficiente a tais modelos (difusos e de pequena escala) de produção de energia e seus potenciais impactos (positivos ou negativos) no meio ambiente.

Justamente em razão disso é que, uma vez delineado o contexto geral dos desafios que a interação entre meio ambiente e energia impõe à regulação jurídica, passa-se a focar especificamente as referidas formas de geração (minigeração e microgeração), notadamente no que se refere ao marco legal que disciplina esses mecanismos, seu potencial para o setor energético e para o meio ambiente, assim como alguns dos meios através dos quais a legislação pode contribuir (ou atrapalhar) para a consolidação de tais iniciativas.

\section{A GERAÇÃO DISTRIBUÍDA COMO MODELO (COMPLEMENTAR) PARA O SISTEMA DE PRODUÇÃO DE ENERGIA}

Ao analisar historicamente o setor de geração e distribuição de energia, o modelo tradicional de atendimento da demanda é marcadamente centralizado. É dizer, no formato que que se tornou largamente predominante, a estruturação do setor é baseada numa reduzida quantidade de usinas geradoras de grande porte, associadas a extensas linhas de transmissão e distribuição até as unidades consumidoras (SEVERINO, 2008, p, 49).

Nos últimos anos, porém, paralelamente ao formato tradicional, vem ganhando destaque outros modelos, reunidos sob o rótulo de geração distribuída, assim entendida "aquela geração de energia localizada próxima ao consumidor, cuja instalação objetiva atendimento prioritário a este, podendo ou não gerar excedentes energéticos comercializáveis para além das instalações do consumidor final" (EPE, 2014, p. 60).

Entre as vantagens da adoção de iniciativas de geração distribuída, costumam ser apontados fatores como (i) a postergação de investimentos em sistemas expansão de distribuição e transmissão, (ii) o menor tempo de implantação, (iii) a redução de perdas, (iv) a diversificação da matriz energética, bem como a (iv) potencial de redução dos impactos no meio ambiente, além da formação de $(v)$ benefícios indiretos, como o surgimento e ampliação de novos mercados de 
equipamentos e serviços, com reflexos econômicos e sociais (ANEEL, 2019, pp. 3-4). ${ }^{9}$

Em suma, comparativamente ao modelo centralizado, o que diferencia a geração distribuída é a circunstância de serem aproveitadas oportunidades de produção de energia "[...] em locais em que não seria instalada uma usina geradora convencional, contribuindo para aumentar a distribuição geográfica da geração de energia elétrica em determinada região" (SEVERINO, 2008, p. 66). Tratase, portanto, de um conjunto de medidas que tornam o sistema energético mais difuso, por meio da inserção de diversas (numerosas) iniciativas locais e que costumam ser caracterizadas como de pequeno porte de geração (voltadas prevalentemente para o atendimento da demanda individual de energia do próprio produtor), de modo que sua aplicação encontra potencial especialmente relevante em áreas urbanas.

Diante desse contexto, uma das consequências da geração distribuída consiste em "[...] inserir a energia produzida por particulares em instalações já alimentadas por uma concessionária local" (SILVEIRA, 2015, p. 47), de modo a viabilizar, inclusive, que unidades localizadas em áreas urbanas e que tradicionalmente são consideradas apenas consumidoras (residências, comércio, indústria) se tornem também fornecedoras de energia para o sistema integrado. É justamente essa operação que caracteriza a minigeração e a microgeração de energia, as quais consistem em duas modalidades entre as diversas possibilidades de geração distribuída.

\section{O MARCO LEGAL DA MICROGERAÇÃO E MINIGERAÇÃO COMO MODALIDADES: ASPECTOS DESTACADOS PARA ÁREAS URBANAS}

Ao disciplinar o marco legal para a comercialização de energia elétrica no país, a Lei Federal n. 10.848/04 estabeleceu que as concessionárias, permissionárias e as autorizadas do serviço público de distribuição de energia elétrica devem garantir atendimento à totalidade do seu mercado (art.

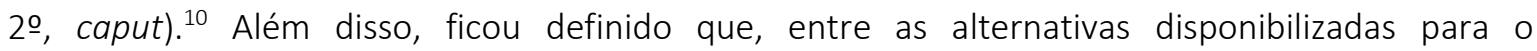
cumprimento da referida obrigação, tais agentes podem se utilizar de energia elétrica proveniente de geração distribuída (art. 2o, $\S 8$ 으 II, a), assim considerada a produção de energia proveniente de empreendimentos conectados diretamente no sistema elétrico de distribuição do comprador, desde que atendidos requisitos específicos (art. 14, Decreto Federal n. 5.163/04).

\footnotetext{
${ }^{9}$ Entre as desvantagens da geração distribuída, são indicadas: (i) aumento da complexidade da operação da rede de distribuição, (ii) necessidade de alterações nos procedimentos das distribuidoras de energia, (iii) intermitência da geração, (iv) alteração dos níveis de curto-circuito da rede.

${ }^{10}$ Sobre o panorama geral do setor no momento da edição da referida legislação, cf. SOUTO (2006).
} 
Posteriormente, através da Portaria Aneel n. 1.447/10, foi definida a Agenda Regulatória Indicativa do setor, na qual uma das atividades priorizadas consistia em diminuir os obstáculos para o acesso de pequenas centrais geradoras aos sistemas de distribuição, culminando na edição da Resolução Normativa Aneel n. 482/12, que estabelece as condições gerais para o acesso de microgeração e minigeração distribuída ao referido sistema, a qual foi parcialmente alterada por outras duas Resoluções Normativas Aneel posteriores (n. 517/12 e n. 687/15). ${ }^{11}$

De acordo com os dispositivos vigentes de referidos diplomas legais, atualmente a micro e a mini geração distribuídas são definidas como centrais geradoras de energia elétrica com capacidade limitada, que utilizam fontes renováveis ou cogeração qualificada e que sejam conectadas na rede de distribuição por meio de instalações na própria unidade consumidora (art. 2ํ, I e II). ${ }^{12}$ O que as diferencia entre si é apenas a potência instalada. Na microgeração, menor ou igual a $75 \mathrm{~kW}$. Na minigeração, superior a $75 \mathrm{~kW}$ e menor ou igual 3MW para fontes hídricas e superior a $75 \mathrm{~kW}$ e menor ou igual 5MW para outras fontes renováveis ou cogeração qualificada. De todo modo, em ambas está presente a mesma característica distintiva em relação às demais modalidades que integram o setor: na microgeração e na minigeração, as unidades tradicionalmente consumidoras passam também a produzir energia, em pequena escala e de forma integrada à rede pública, deixando de exercer apenas papel passivo (de utilização energia elétrica disponibilizada externamente na rede).

É o que pode ocorrer, por exemplo, com a instalação de painéis solares ou de turbinas eólicas na cobertura de edificações urbanas (industriais, comerciais ou residenciais). Por meio da conexão entre o sistema público e pequenas centrais geradoras, movidas a fontes renováveis ou por cogeração qualificada, a demanda da edificação passa a ser prioritariamente atendida pela energia gerada no próprio local. Apenas quando e na medida em que a eletricidade gerada localmente não for suficiente para o consumo próprio é que a edificação passa a ser abastecida com a energia fornecida pela concessionária pública.

\footnotetext{
${ }^{11}$ Esclarece-se que, ao longo do texto, quando não houver indicação em sentido diverso, os dispositivos legais referenciados constam da Resolução Normativa Aneel n. 482/12 e suas alterações posteriores.

12 Entre as principais fontes renováveis, pode-se mencionar a hidráulica, a solar, a eólica, a maremotriz, a biomassa etc. Já a cogeração consiste no "processo operado numa instalação específica para fins da produção combinada das utilidades calor e energia mecânica, esta geralmente convertida total ou parcialmente em energia elétrica, a partir da energia disponibilizada por uma fonte primária" (art. 3ำ, I Resolução Normativa Aneel n. 235/06). É o que ocorre, por exemplo, quando o calor que naturalmente se dissipa na utilização de certo combustível (gás, petróleo etc.), o que pode acarretar perdas superiores a $70 \%$ da energia contida, é reaproveitado para a produção de vapor, ar quente ou refrigeração a ser empregado em usos produtivos (industrial, residencial ou comercial). Para que seja considerada cogeração qualificada, de modo a se enquadrar nas regras de microgeração e minigeração distribuída, devem ser atendidos requisitos específicos de racionalidade energética (art. 4ㅇ da Resolução Normativa Aneel n. 235/06).
} 
Além disso, é possível que num determinado mês a energia gerada pelo minigerador ou microgerador seja superior à demanda da edificação onde foram instalados. Para esses casos, foi criado o sistema de compensação, no qual a energia ativa injetada por determinada unidade consumidora com microgeração ou mingeração distribuída é cedida à distribuidora local, por meio de empréstimo gratuito, sendo posteriormente compensada com o consumo de energia elétrica ativa dessa mesma unidade (art. 2으, III). É dizer, com o sistema de compensação se estabelece uma espécie de relação de crédito e débito de energia entre a unidade consumidora com minigeração ou microgeração e a concessionária pública, que pode culminar na redução do valor da tarifa a ser paga pela unidade consumidora. ${ }^{13}$

Isso porque, quando a energia gerada na unidade consumidora for superior à sua demanda, o excedente é transferido e armazenado no sistema de distribuição público, de modo a se formarem créditos para futura utilização pela unidade consumidora. Posteriormente, num período de até 60 meses (art. 6으, § 1으), nos momentos em que a demanda for superior à sua capacidade de (mini ou micro) geração, tais créditos são aproveitados pela unidade consumidora, de modo que a concessionária devolve a mesma quantidade de energia que anteriormente foi armazenada na rede pública, sem que isso represente novo fornecimento de energia elétrica e, portanto, não havendo cobrança de tarifa sobre tal montante.

Além disso, para estimular a proliferação dessas iniciativas e lhes conferir escala, a disciplina jurídica da micro e mini geração distribuída e do sistema de compensação estabeleceu outros mecanismos, que podem ser utilizados de modo a potencializar a utilização de tais modalidades em áreas urbanas.

É o caso, por exemplo, dos chamados empreendimentos com múltiplas unidades consumidoras, os quais podem realizar micro ou mini geração de forma agrupada, definindo-se o percentual de energia excedente que será atribuído a cada unidade consumidora para fins de compensação (art. 2o, VI), cuja aplicação é especialmente adequada para condomínios edilícios (residenciais, comerciais ou industriais), de modo que a instalação de microgeradores em áreas comuns do condomínio possa beneficiar (proporcionalmente) todas as unidades imobiliárias (OCB, 2019).

Outro mecanismo nessa mesma direção (i.e., potencializar a utilização de micro ou mini

\footnotetext{
${ }^{13}$ Independentemente do volume de créditos criado, no mínimo haverá a cobrança do valor referente ao custo de disponibilidade (consumidores do grupo B) ou da demanda contratada (consumidores do grupo A), de modo que, mesmo no sistema de compensação, haverá pagamentos à concessionária pública (art. 7o, I).
} 
geração em áreas urbanas) é a denominada geração compartilhada, na qual unidades consumidoras de proprietários distintos e sem qualquer vinculação prévia entre si (ou seja, que não mantenham sequer vínculo condominial) se reúnem sob a forma de cooperativa ou consórcio, de modo que o local de geração possa ser diferente daquele no qual a energia excedente será compensada (art. 2º, VII).

O mesmo potencial para áreas urbanas também pode ser vislumbrado na figura conhecida como autoconsumo remoto, viabilizando a energia gerada numa unidade consumidora possa ser aproveitada em outro local que seja titularizado pela mesma pessoa jurídica ou física, de modo que a capacidade excedente de geração de energia de uma edificação seja destinada ao (e considerada no) consumo de outra edificação que eventualmente apresente défice de capacidade de geração (art. $\left.2^{\circ}, \mathrm{VIII}\right)$.

\section{IMPACTOS E POTENCIAL DA MICROGERAÇÃO E MINIGERAÇÃO DE ENERGIA EM RELAÇÃO AO MEIO AMBIENTE}

Entre os benefícios decorrentes da geração distribuída, inclusive nas modalidades de microgeração e minigeração, costuma ser apontada a redução dos impactos ambientais, em comparação com o cenário de aprofundamento do modelo tradicional do setor energético.

Isso porque, uma das possíveis consequências da produção de energia em pequena escala individual, de forma difusa e em locais já ocupados para outros usos (notadamente com processos de urbanização já consolidados) é a diminuição da necessidade de conversão do uso do solo em extensas áreas (v.g., para enchimento de reservatórios ou para instalação de redes de transmissão), tal como geralmente ocorre com grandes projetos de usinas geradoras, frequentemente instaladas em áreas muito distantes dos centros consumidores. Em termos de impactos ambientais, isso pode representar a diminuição de pressões por desmatamento e de urbanização desorganizada de novas áreas, além de evitar ou minimizar a intervenção em regiões que ainda preservem suas condições naturais e a respectiva biodiversidade.

De mais a mais, a diversificação da matriz energética, que caracteriza a microgeração e a minigeração distribuídas, pode aprofundar o processo de substituição das formas mais poluentes de geração de energia (petróleo, carvão, gás etc.), as quais usualmente são utilizadas pelas instalações convencionais, por fontes menos degradantes (solar, eólica etc.), bem como pode contribuir para a melhoria da eficiência energética de unidades geradoras (notadamente caso da cogeração 
qualificada).

Além disso, não obstante com uma função inicialmente mais simbólica, a adesão a sistemas de microgeração e minigeração, por indivíduos que tradicionalmente apenas ocupavam a posição de consumidores, pode contribuir para intensificar a percepção e a atuação da sociedade em geral em temas ligados à energia e meio ambiente, consistindo em fator que pode impulsionar a participação da coletividade e a consolidação da cidadania ambiental (FISCHER, 2012).

Portanto, para além dos benefícios que possam ser verificados no próprio setor elétrico, a identificação e concretização do potencial de iniciativas de microgeração e minigeração distribuída também desempenha função que não é desprezível para a compatibilização (i.e., redução da litigiosidade) da relação entre (a proteção e promoção do) meio ambiente e (a produção e consumo de) energia, num contexto voltado ao paradigma de desenvolvimento sustentável, com implicações positivas inclusive para espaços urbanos.

Acerca da situação atual e do potencial da microgeração e minigeração distribuída foi elaborada a Nota Técnica n. 0017/2015/SDR/ANEEL, para subsidiar o processo de discussão com os atores do setor que culminou com a edição de Resolução Normativa Aneel n. 687/15 (ANEEL, 2019).

De acordo com a referida Nota Técnica, até o final do ano de 2014, já haviam sido instalados minigeradores ou microgeradores integrados à rede pública de distribuição e ao sistema de compensação em 533 unidades consumidoras do país, distribuídas entre estabelecimentos residenciais $(69 \%)$, comerciais $(18 \%)$, consumidores do grupo $A(7 \%)$, industriais $(3 \%)$, rurais $(2 \%)$ e do poder público (1\%), que somadas são capazes de gerar até $7.320 \mathrm{~kW}$ de energia elétrica.

No mesmo documento técnico, em seu Anexo II, também foram divulgados os resultados de pesquisa realizada pela agência reguladora com os responsáveis por unidades consumidoras que instalaram sistemas de microgração e minigeração distribuída. ${ }^{14}$ Parcela significativa dos entrevistados (62\%) declararam que as expectativas que tinham em relação à iniciativa que adotaram foram atingidas ou superadas, enquanto que $36 \%$ afirmaram estarem satisfeitos mesmo que suas expectativas iniciais ainda não tenham se concretizado, sendo que apenas $2 \%$ dos respondentes se mostraram insatisfeitos com a adoção dessa forma de geração distribuída. Tal avaliação possivelmente esteja relacionada com os impactos que os minigeradores e microgeradores provocam na tarifa paga nessas unidades consumidoras, na medida em que foram apontadas

\footnotetext{
${ }^{14}$ Embora a amostra da pesquisa contenha número bastante reduzido de respondentes, trata-se de um indicativo sobre como os consumidores percebem os resultados da instalação de equipamentos de geração distribuída.
} 
reduções superiores a $75 \%$ em $26 \%$ dos entrevistados, mesmo percentual dos que indicaram diminuição entre $50 \%$ e $75 \%$ na tarifa mensal, enquanto que em $29 \%$ dos casos a variação se situou entre $25 \%$ e $50 \%$, sendo que apenas $19 \%$ verificaram economia inferior a $25 \%$ ou não souberam quantificar se houve modificação.

Além diagnosticar o cenário atual, também foi realizada a análise do impacto regulatório (Anexo V), com o objetivo de estimar o número de consumidores residenciais e comerciais que potencialmente irão instalar microgeração solar fotovoltaica no horizonte de $2014-2024 .{ }^{15}$ No cenário mais favorável à adoção dessas iniciativas, projeta-se que 620.370 residências e 82.216 estabelecimentos comerciais devem aderir à integração de microgeradores e minigeradores à rede pública no referido período, com potencial para produzirem conjuntamente $2.683 \mathrm{MW}$ de energia elétrica. ${ }^{16}$

\section{REGULAÇÃO JURÍDICA E GERAÇÃO DISTRIBUÍDA DE ENERGIA EM ÁREAS URBANAS: COMO O DIREITO PODE AJUDAR (OU ATRAPALHAR)}

Para que a geração distribuída possa atingir seu potencial em áreas urbanas, inclusive nas modalidades de microgeração e minigeração, de modo a aprimorar o perfil do setor de energia do país e auxiliar na mitigação dos impactos ambientais associados, há diversos obstáculos institucionais e desafios regulatórios que precisam ser enfrentados. Nesse sentido, considerado a partir da perspectiva de um sistema de incentivos para adoção de determinados comportamentos, o ordenamento jurídico pode ajudar ou atrapalhar na adesão a iniciativas de geração difusa, local e de pequena de escala, características que marcam a geração distribuída em áreas urbanas.

Especificamente no caso brasileiro, entre outros fatores, não parece despropositado afirmar que tais desafios institucionais e regulatórios estão associados, inclusive, à multiplicidade de instituições públicas (de Estado) cuja atuação pode interferir na formação de um ambiente (jurídico) de incentivo ou desestímulo à adoção de medidas de microgeração e minigeração distribuídas. Dito

\footnotetext{
${ }^{15}$ A escolha pela avaliação desse tipo de geração (fotovoltaica) se deve ao fato de ser a modalidade mais largamente utilizada na atualidade. É certo, porém, que o potencial efetivo é ainda superior, se consideradas as demais formas possíveis de microgeração ou minigeração distribuída (eólica, hídrica, cogeração qualificada etc.) e também a possibilidade de geração de pequena escala em atividades industriais.

${ }^{16}$ Para efeitos de comparação, as vinte unidades geradoras da Usina de Itaipu, que fornece $15 \%$ da energia consumida no Brasil e $75 \%$ do consumo paraguaio, têm $14.000 \mathrm{MW}$ de potência instalada. Portanto, apenas para uma forma de minigeração distribuída (solar) em estabelecimentos residenciais e comerciais, a estimativa da ANEEL é de que há potencial para acrescentar ao sistema energético algo em torno de 19,16\% da potência instalada da Usina de Itaipu.
} 
de outro modo, para além das instituições que integram diretamente o arranjo institucional de regulação da produção energética no país (MME, ANEEL, ONS etc.), a disciplina jurídica da matéria também é significativamente influenciada por ações (legislativas e administrativas) da alçada de diversos outros órgãos, desde o plano federal até os governos locais. Essa interdependência - da regulação jurídica do setor energético com ações estatais promovidas por órgãos que não integram diretamente sua estrutura de regulação - pode ser constada em distorções existentes no sistema tributário, o que será analisado no próximo item, a título de exemplificação. É certo, porém, que diversas outras situações semelhantes - nas quais as opções adotadas no âmbito da regulação jurídica ajudam ou atrapalham a concretização do potencial da microgeração e minigeração distribuída no país - podem ser identificadas nos mais variados níveis, desde o estabelecimento de regras licitatórias para a contratação de obras e serviços pelo poder público, passando até mesmo pela formação da legislação municipal relativa ao uso e ocupação do solo e à aprovação de edificações urbanas.

\section{O EXEMPLO DA TRIBUTAÇÃO NA MICROGERAÇÃO E MINGERAÇÃO DISTRIBUÍDA}

Para além de sua função arrecadatória, a tributação desempenha significativa influência na adoção dos comportamentos de agentes privados, os quais tendem a evitar iniciativas cujos custos sejam majorados por exações fiscais impostas excessiva ou injustificadamente pela legislação. É o que ocorre no tratamento tributário conferido ao sistema de compensação de energia, um dos principais instrumentos para motivar a instalação de equipamentos de minigeração e microgeração distribuída.

Muito embora a Resolução Normativa Aneel n. 482/12 qualifique como empréstimo gratuito a operação por meio da qual o excedente de energia gerado pela unidade consumidora é cedido à rede pública de distribuição, o aproveitamento dos créditos obtidos no sistema de compensação de energia vem sendo considerado fato gerador para a incidência de tributos federais e estaduais. Nesse sentido é que desponta a observação feita pela própria $\operatorname{ANEEL}(2014$, p. 15), ou seja, “[...] para o cálculo do montante de impostos a pagar, algumas distribuidoras aplicam a tarifa final com impostos (PIS/COFINS e ICMS) [...]" sobre toda a energia consumida no mês, inclusive a parcela que tenha origem na utilização de créditos lançados no sistema de compensação.

Esse modelo de tratamento tributário causa importante distorção, na medida em que a unidade consumidora é obrigada a pagar tributos incidentes sobre a energia elétrica que ela própria gerou, em momento anterior, de modo a tornar menos competitivo o custo unitário da energia produzida 
por meio de microgeração e minigeração, em comparação com a fornecida diretamente pela concessionária, o que constitui fator de desestímulo à adoção de medidas de geração distribuída de pequena escala.

No que se refere ao PIS/COFINS, tal situação foi parcialmente corrigida com a edição da Lei Federal n. 13.169/15, que resultou na conversão da Medida Provisória n. 675/15, na qual foram reduzidas a zero as alíquotas de tais tributos em operações relativas à energia elétrica ativa fornecida pela distribuidora, na mesma quantidade correspondente àquela produzida pela unidade consumidora por meio de microgeração ou minigeração de energia, no âmbito do sistema de compensação disciplinado pela Aneel (art. 8º). De outra parte, ao sancionar a referida lei de conversão, argumentando que se trata de renúncia de receita não condizente com o contexto econômico atual, o Poder Executivo vetou dispositivo inserido pelo Poder Legislativo (art. 9o), que estabelecia alíquota zero de PIS/COFINS incidentes sobre produtos utilizados na fabricação de itens e equipamentos destinados à microgeração e minigeração de energia, o que reduziria os custos de implantação e, por conseguinte, aumentaria a atratividade da geração distribuída de pequena escala.

Na esfera da tributação estadual também há distorções tributárias a serem superadas. Isso porque, ao estabelecer a disciplina para fins da emissão de documentos fiscais nas operações internas relativas à circulação de energia elétrica, que estejam sujeitas a faturamento sob o Sistema de Compensação de Energia Elétrica da Aneel, o Convênio Confaz n. 6/13 viabilizou a incidência de ICMS sobre o valor atribuído à energia excedente gerada pela própria unidade consumidora - através de minigeração ou microgerção - que posteriormente é entregue pela concessionária pública. Não obstante a regra geral estabelecida, acima indicada, diversos Estados federativos celebraram Convênios específicos no âmbito do Confaz, por meio do qual foram autorizados a conceder isenção de ICMS incidente sobre a energia elétrica pela concessionária, em decorrência do aproveitamento de créditos do sistema de compensação de geração distribuída através de microgeração e minigeração. ${ }^{17}$ Além disso, em outros Estados da federação há legislação estadual específica na mesma direção, ou seja, isentando de ICMS o fornecimento de energia elétrica correspondente à geração da própria unidade consumidora. ${ }^{18}$

\footnotetext{
${ }^{17}$ Do que são exemplos os Estados de Goiás, Pernambuco e São Paulo (Convênio Confaz n. 16/15), Rio Grande do Norte (Convênio Confaz n. 44/15), Ceará e Tocantins (Convênio Confaz n. 52/15) e Bahia, Maranhão, Mato Grosso e Distrito Federal (Convênio Confaz n. 130/15).

${ }^{18}$ Do que é exemplo a Lei Estadual n. 20.824/13, de Minas Gerais.
} 


\section{CONCLUSÃO}

O presente artigo se propôs a apresentar reflexões (iniciais) sobre o papel da microgeração e minigeração de energia - como instrumento difuso, local e de pequena escala de geração distribuída em áreas urbanas - no âmbito da relação entre setor energético e meio ambiente. À guisa de considerações finais, retomam-se algumas das posições manifestadas ao longo do texto:

(a) o sistema jurídico nacional adota o modelo de desenvolvimento sustentável como paradigma para a relação entre proteção do meio ambiente e realização de atividades produtivas, de modo que o próprio conteúdo da dignidade da pessoa humana - como princípio-fim do Estado (e do Direito) pressupõe a compatibilização de valores (jurídicos) ambientais, sociais e econômicos, os quais atuam num cenário de intensa conflituosidade;

(b) a intensa conflituosidade inerente ao desenvolvimento sustentável se manifesta de modo marcante na relação entre meio ambiente e energia, na medida em que a geração, distribuição e consumo de energia (elétrica) constituiu insumo indispensável para a expansão da atividade econômica do país e para a melhoria das condições de vida das pessoas, mas, concomitantemente, também é fonte de degradação ambiental em diversos níveis, inclusive no que diz respeito aos efeitos que as atividades humanas causam na mudança do clima;

(c) o modelo de geração de energia no país e, por conseguinte, a regulação jurídica do setor, inclusive no que se refere ao meio ambiente, é marcadamente centralizado e está tradicionalmente focado na implantação e operação de grandes empreendimentos, capazes de individualmente gerar expressiva quantidade de energia e que acarretam também significativo potencial de degradação ambiental;

(d) nos últimos anos, em paralelo a esse modelo tradicional, ganha espaço a denominada geração distribuída, que consiste no aproveitamento do potencial de produção de energia onde normalmente não seriam instaladas unidades geradoras, tornando o sistema energético mais difuso, incorporando iniciativas locais e de pequena escala, sendo aplicável a espaços urbanos, voltada a atender prioritariamente à demanda da própria unidade consumidora, do que são exemplos a microgeração e a mingeração distribuídas;

(e) no Brasil, por meio da disciplina jurídica conferida pela Resolução Normativa Aneel n. 482/12 e suas alterações (n. 517/12 e n. 687/15), a microgeração e a minigeração distribuída é configurada pela instalação de centrais geradoras de energia elétrica com capacidade limitada (até 5MW), que utilizem fontes renováveis ou cogeração qualificada e que estejam conectadas na rede de 
distribuição por meio de instalações na própria unidade consumidora, podendo ser implementada em edificações urbanas (residenciais, comerciais e industriais). Uma vez conectada à rede da concessionária pública, a energia produzida por minigeração ou microgeração distribuída é utilizada para atender à demanda da própria unidade consumidora que a produziu, sendo que o excedente pode ser aproveitado em períodos posteriores, por meio de créditos gerados no âmbito do sistema de compensação de energia;

(f) além de aprimorar o próprio setor energético, a minigeração e microgeração distribuída pode trazer benefícios para a relação entre meio ambiente e produção (e consumo) de energia, na medida em que a implementação de iniciativas difusas, locais e de pequena escala em áreas urbanas aproveitando espaços já ocupados para outros usos (residencial, comercial ou industrial), reduzindo a necessidade de conversão do solo para a implantação de grandes empreendimentos de energia e suas extensas redes de distribuição, diminuindo as pressões sobre desmatamento e urbanização descontrolada de áreas ambientalmente relevantes (inclusive, para conservação da biodiversidade), além de facilitar a diversificação da matriz energética (com a utilização de fontes renováveis) e de estimular a promoção de valores associados à cidadania ambiental (na medida em que mais pessoas deixam o papel de meros consumidores e passam a atuar ativamente na geração da energia que consomem);

(g) até o ano de 2024, as projeções realizadas pelos órgãos regulatórios do setor indicam que o potencial de expansão dos projetos de minigeração e microgeração distribuída é bastante significativo em áreas urbanas, podendo contribuir com a geração de cerca de $2.683 \mathrm{MW}$ de energia elétrica, distribuídos em mais de 700 mil estabelecimentos (residenciais, comerciais e industriais) que podem ser responsáveis por atender (parte de) sua demanda própria por energia;

(h) o efetivo aproveitamento do potencial da microgeração e minigeração distribuída está diretamente relacionado à superação de desafios institucionais e regulatórios do setor, inclusive decorrentes do impacto de ações administrativas e legislativas adotadas por entes que não integram diretamente a estrutura do setor energético, do que são exemplos distorções no regime de tributação, nas condições fixadas para a contratação e execução e serviços públicos em geral, além da formatação da legislação municipal que disciplina o uso e ocupação do solo urbano, notadamente quanto aos requisitos para aprovações de edificações.

\section{REFERÊNCIAS BIBLIOGRÁFICAS}


ANEEL - Agência Nacional de Energia Elétrica. Nota Técnica n. 0017/2015/SDR/ANEEL. Disponível em www.aneel.gov.br/aplicacoes/audiencia/arquivo/2015/026/documento, acessado em 7 de janeiro de 2019.

. Mini e microgeração distribuída: sistema de compensação de energia elétrica. Brasília:

ANEEL, 2014.

. Nota Técnica n. 43/2010-SRD/ANEEL. Disponível em

www.aneel.gov.br/aplicacoes/consulta_publica/documentos, acessado em 07 de janeiro de 2019.

BELL, Simon; MORSE, Stephen. Sustainability Indicators: measuring the immeasurable? 2. ed.

Londres: Earthscan, 2008.

COSTA, Maria Assunção. Dicionário brasileiro do direito da energia, do petróleo e do gás natural. São Paulo: Atlas, 2014

EPE - Empresa Brasileira de Pesquisa Energética. Avaliação da eficiência e geração distribuída para os próximos dez anos (2014-2023). Brasília: EPE, 2014.

. Consumo final e conservação de energia elétrica (1970-2005). Brasília: EPE, 2006.

FERREIRA, Renata Marques; FIORILLO, Celso Antônio Pacheco. Curso de Direito da Energia. 3.ed. São Paulo: Saraiva, 2015. FREITAS, Juarez. Sustentabilidade: direito ao futuro. 2.ed. Belo Horizonte: Forum, 2012.

FGV - Fundação Getúlio Vargas. Comissão Mundial sobre Meio Ambiente e Desenvolvimento: Nosso Futuro Comum. 2. ed. Rio de Janeiro: Editora da FGV, 1991.

FISCHER, Fabiana Janaina Vargas. Cidadania ambiental global e sustentabilidade. in: Revista Eletrônica Direito e Política. vol. 7, n. 1. Itajaí: Univali, 2012.

MANCUSO, Rodolfo de Camargo. Interesses difusos: conceito e legitimação para agir. São Paulo: Revista dos Tribunais, 2011.

MMA - Ministério do Meio Ambiente (Brasil). Declaração Final da Conferência das Nações Unidas sobre Desenvolvimento Sustentável: o Futuro que Queremos. Disponível em:

http://www.mma.gov.br/port/conama/processos/61AA3835/O-Futuro-que-queremos1.pdf. Acessado em 13 de janeiro de 2019.

McSHANE, Kate. Anthropocentrism vs. Nonanthropocentrism: why should we care? in:

Environmental Values. n. 16. Ilha de Harris (Inglaterra): White Horse Press, 2007. 
NOLLON, John R. Protecting the environment through land use law: standing ground. Washington: Environment Law Institute, 2014.

OCB - Organização das Cooperativas Brasileiras. Coopere e gere sua própria energia. Disponível em file://C:/Users/Leonardo\%20Papp/Downloads/Coopere\%20e\%20gere\%20sua\%20pr\%C3\%B3pria\% 20energia.pdf. Acessado em 13 de janeiro de 2019.

PERRET, Bernard. O capitalismo é sustentável? São Paulo: Edições Loyola, 2011.

SARLET, Ingo Wolfgang; FENSTERSEIFER, Tiago. Estado socioambiental e mínimo existência (ecológico?). in: SARLET, Ingo Wolfgang (org.). Estado Socioambiental e Direitos Fundamentais. Porto Alegre: Livraria do Advogado, 2010.

SEVERINO, Mauro Moura; et ali. Geração Distribuída: discussão conceitual e nova definição. in: Revista Brasileira de Energia. vol. 14, n. 1. Itajubá (MG): Sociedade Brasileira de Planejamento Energético, 2008.

SILVA, José Afonso da. Aplicabilidade das normas constitucionais. São Paulo: Revista dos Tribunais, 1998.

SILVEIRA, André Luiz; et alli. Desenvolvimento tecnológico em geração distribuída: gerenciamento e monitoração de uma microgeração solar. in: E-tech: tecnologias para a competitividade industrial. vol. 8, n. 1. Florianópolis: Fiesc-Senai, 2015.

SOARES, Cláudia Alexandra Dias. Direito das energias renováveis. Lisboa: Almedina, 2014. SOUTO, Marcos Juruena Vilella. Breve apresentação do novo marco regulatório do setor elétrico brasileiro. in: Revista da Procuradoria Geral do Estado do Rio de Janeiro. n. 60. Rio de Janeiro: Cejur, 2006.

Trabalho enviado em 27 de janeiro de 2019

Aceito em 01 de outubro de 2019 